\title{
Associations between Sleep Quality and Different Measures of Obesity in Saudi Adults
}

\author{
Hala Hazam AL-Otaibi ${ }^{1}$ \\ ${ }^{1}$ Department of Food Sciences and Nutrition, Community Nutrition, College of Agriculture and Food Science, \\ King Faisal University, AL-Hasa, Saudi Arabia \\ Correspondence: Department of Food Sciences and Nutrition, Community Nutrition College of Agriculture and \\ Food Science, King Faisal University, AL-Hasa, Saudi Arabia. E-mail: hhalotaibi@kfu.edu.sa; \\ halaalotaibi5m@gmail.com
}

Received: February 27, 2016 Accepted: March 23, 2016 Online Published: May 6, 2016

doi:10.5539/gjhs.v9n1p1

URL: http://dx.doi.org/10.5539/gjhs.v9n1p1

\begin{abstract}
The prevalence's of overweight and obesity have grown to epidemic proportions in Saudi Arabia the past few years, epidemiological studies have suggested that sleeping for less than seven hours/day is associated with increased morbidity in terms of the development of obesity. The aim of this study was to examine the association between sleep quality and different measures of obesity (body mass index, waist circumference and body fat percentage) and some lifestyle habits among female university students. A cross-sectional study targeted a convenience sample of 233 undergraduate female students at King Faisal University (KFU) in AL-Hasa, Saudi Arabia. The results indicated that poor sleep quality was common in students $(54 \%)$ with mean total sleeping hours of five hours/day. Poor sleep quality was associated with overweight/obese (OR 4.210, $\mathrm{P}=0.000)$, at risk waist circumference (OR 2.005, $\mathrm{P}=0.009)$, moderate/high body fat percentage (OR 1.058, $\mathrm{P}=0.025)$, low physical active (OR 2.045, $\mathrm{P}=0.037$ ), and skipping breakfast (OR 2.710, $\mathrm{P}=0.003)$. In conclusion, the present study highlights the prevalence of poor sleep quality among female university students in Saudi Arabia, and they support previously published studies indicating that poor sleep quality was associated with different measures of obesity and some of lifestyle habits. Sleep quality is an untraditional approach that might be used to prevent or treat overweight and obesity.
\end{abstract}

Keywords: sleep quality, obesity, female, university students

\section{Introduction}

The prevalence's of overweight and obesity have grown to epidemic proportions in Saudi Arabia. Recent studies of Saudi women reported a prevalence between 29\% to 33.5\% (Memish et al., 2014; Darwish et al., 2014), which is similar to a worldwide prevalence of $15 \%$ to $40 \%$ (WHO, 2015). Efforts to decrease obesity in Saudis have not yielded great success, despite the national campaign against overweight and obesity (MOH, 2015).

Obesity is a multi-factorial condition that is thought to be the result of complex interactions between genetic and environmental factors (Chaput et al., 2014). Traditionally, studies targeting obesity prevention have focused on physical activity and dietary behaviors. However, in the past few years, epidemiological studies have suggested that sleeping for less than seven hours/day is associated with increased morbidity in terms of the development of obesity, hypertension, cardiovascular disease and type 2 diabetes (Knutson et al., 2010). Sleep quality and duration are modifiable risk factors that are known to be associated with high body mass index, waist circumference, and body fat percentage, and some lifestyle habits (e.g. physical activity, dietary habits, and influence of technology).

Recent evidence has shown that poor sleep quality may affect an individuals' energy intake and expenditure resulting in obesity (Taheri, 2006; Bayon et al., 2014), and perhaps also low physical activity (McClain et al., 2014), skipping breakfast (Kim et al., 2011), high coffee/tea intake (Cheng et al., 2012), and low fruit, vegetable intake (Tu et al., 2012). Sleeping less than seven hours/day has increased in incidence in American young adults from 15.6\% in 1960 to 43\% in 2009 (National Sleep Foundation of America). In addition, poor sleep quality was prevalent in female college students in Saudi Arabia (69.1\%) who slept a mean of only 4.77 hours sleep/night in across sectional survey conducted among 400 medical students at Jazan University (Mahfouz et al., 2013). Among Saudi adolescents (10 to 19-year olds), there are studies investigated sleep duration and obesity and 
found an inverse association between overweight/obesity and short sleep duration (less than seven hours/day) (Al-Hazzaa et al., 2012; Bawazeer et al., 2009). Review on sleep medicine in Saudi Arabia emphasizing the need for more sleep research to address the prevalence of different sleep disorders among various segments of the population related to obesity and lifestyle (Bahammam, 2011). To our knowledge, there have been little or no reported data on sleep duration, quality, and obesity in adults, this study hope to fill this gap.

Thus, the aim of this study was to examine the association between sleep quality and different measures of obesity (body mass index, waist circumference and body fat percentage), and some lifestyle habits (physical activity, dietary habits, and influence of technology) among female university students.

\section{Material and Methods}

\subsection{Design and Subjects}

The cross sectional study recruited 233 female students at King Faisal University (KFU) in AL-Hasa, Saudi Arabia. Students were recruited by convenience sampling over the period of November to December, 2015. Three trained nutrition students were available in the main hall of the College of Agriculture and Food Science (female section) to explained the study purpose to potential participants. The nutrition students were gave them the choice to participate in the study or withdraw at any time. The participants were informed that the return of the questionnaire implied their informed consent. Participants who agreed to participate fill the questionnaire in the main hall (took about 5-10 minutes to complete). Short interview and anthropometric measurements were taken after filling the questionnaire (took about 10 minutes). The study inclusion criteria were females of at least 18 years who were full-time undergraduate students in the College of Agriculture and Food Science at KFU, not suffering from chronic diseases, and not pregnant. Ethical approval was obtained from the College of Agriculture and Food Science to conduct the study.

\subsection{Instrument}

The questionnaire included:

2.2.1 Socio-demographic questions were asked about age, marital status, having children, household income, and one question about health status (How would you say your health? good, not well, and poor).

\subsubsection{Anthropometric measurements and indicators}

Researchers took all the measurements (height, weight, waist circumference, and percentage of body fat). Body mass index (BMI) was computed and categorized according to the World Health Organization guidelines (WHO,1998). The waist circumference was measured and categorized according to the WHO guidelines (WHO, 1998) as normal $(<88 \mathrm{~cm})$ or at risk $(\geq 88)$. Percentage of body fat was determined using the Omron Body Fat Monitor HBF-306 hand-to-held bioelectrical impedance meter (Vasudev et al., 2004), and it was categorized as either low $(<20 \%)$, normal $(20-29.9 \%)$, moderate $(30-35 \%)$, and high $(>35 \%)$. For analysis, the data was grouped into two groups: normal $(\leq 29.9 \%)$ and moderate/high $(\geq 30 \%)$.

\subsubsection{The Pittsburgh Sleep Quality Index (PSQI)}

For evaluation of sleep quality during the past month, we used the PSQI (Buysse et al., 1989) which assesses seven components of sleep: sleep quality, sleep latency, sleep duration, sleep efficiency, sleep disturbances, use of sleep medications, and daytime dysfunction. Scoring for each component ranges from zero to three, whereby three indicates poor sleep. The summation of the seven components ranges from zero to 21 with higher scores indicating poorer sleep quality. Buysse et al., (1989) set up a cut-off score of $>5$ to indicate poor sleep quality and $\leq 5$ to indicate good sleep quality. The internal consistency reliability of the questionnaire and its seven components is good to high, with Cronbach's alpha coefficients ranging from .71 to .85 .

\subsubsection{Physical Activity}

Physical activity was assessed using the International Physical Activity Questionnaire (IPAQ-short form). Participants were asked to recall their physical activities during the past 7-days including walking and moderate to vigorous activity, according to frequency (days/week) and duration (hours and minutes/day). According to the spent MET (Metabolic Equivalent of Task) minutes/week score, subjects were categorized as either low, moderate or high on activity (Al-Hazzaa, 2006).

\subsubsection{Lifestyle Habits}

Lifestyle habits were assessed by asking participants to recall the frequency as: (daily, 4-5 times/week, 2-3 times/week, rarely/never) with which they skipped breakfast, ate fruit/vegetables, drank coffee/tea. For analysis, the data was grouped into two groups: $<3$ times/week and $\geq 3$ times/week. One question about used the internet in 
bed (Do you use internet in bed? yes, no)

\subsection{Analysis}

The participants were classified into two groups: $>5$ scores (PSQI) poor sleep quality and $\leq 5$ scores (PSQI) good sleep quality. The data were analyzed using SPSS statistical package (version 19). All data was double-checked for normality. $t$-tests were used to compare differences between the groups on the continuous variables. Chi-square analysis was used to examine potential differences between the categorical variables. Multivariable logistic regression was conduct to determine the association between sleep quality and different measures of obesity and some of lifestyle habits in a sample of students. The regression model included variables that significantly difference between the groups. The level of statistical significance was set at $\mathrm{P}<0.05$.

\section{Results}

Table 1 shows that the prevalence of poor sleep quality was $54 \%$ among students with $5.89 \pm 1.15$ hours/day. Furthermore, most of the students in both groups were single, $23 \%$ of the poor sleepers had children, and $51.6 \%$ of them felt unwell, with significant differences between the groups (see Table 1). The mean of weight and BMI and BMI category were significantly different between the groups. Three-quarters $(77.6 \%)$ of the good sleepers were of normal weight, with only one student obese. In contrast, almost forty percent (39.7\%) of the poor sleep had moderate/high body fat percentage, and $38.1 \%$ had an at risk waist circumference. Significant differences in total PSQI mean scores existed between the good sleeper (4.43 \pm 1.38$)$ compared to poor sleepers $(9.14 \pm 1.69)$. The seven components of sleep were also significantly higher in the poor sleepers (see Table 2).

In addition, there were significant differences between the groups in terms of physical activity MET minutes/week and level of physical activity, skipping breakfast, and fruit/vegetable intake $(\mathrm{P}=0.016,0.011,0.025$, 0.031; respectively). Further, poor sleepers drank more tea/coffee and used the internet in bed, but there was no significant difference between the groups on this variable (see Table 3). Multivariate logistic regression analyses showed that poor sleep quality was associated with different measures of obesity. Poor sleepers were four-times more likely to be overweight/obese (OR 4.210, $\mathrm{P}=.000$ ), two-times more likely to have an at risk waist circumference (OR 2.005, $\mathrm{P}=0.009$ ), and a slightly increased risk of moderate/high body fat percentage (OR $1.058, \mathrm{P}=0.025)$. Furthermore low physical activity ( $\mathrm{OR} 2.045, \mathrm{P}=0.037)$ and skipping breakfast (OR 2.710, $\mathrm{P}=0.003$ ) were associated with poor sleep quality among the students (see Table 4).

Table 1. Difference in demographic characteristics, anthropometric measurements and indicators between good and poor sleepers

\begin{tabular}{llll}
\hline Variable & $\begin{array}{l}(\mathrm{PSQI}) \leq 5 \\
\text { Good sleepers } \\
107(46 \%)\end{array}$ & $\begin{array}{l}\text { (PSQI) }>5 \\
\text { Poor sleepers } \\
126(54 \%)\end{array}$ & $\mathrm{P}\left(\mathrm{t}-\mathrm{test} / \mathbf{s}^{2}\right)$ \\
\hline $\begin{array}{l}\text { Demographic } \\
\text { age }\end{array}$ & $22.37 \pm 9.64$ & $22.71 \pm 10.93$ & 0.807 \\
\hline Marital status & & \\
Married & $29(27.1 \%)$ & $37(29.4 \%)$ & 0.177 \\
Single & $78(72.9 \%)$ & $89(70.6 \%)$ & \\
Having children & $8(7.47 \%)$ & $29(23.01 \%)$ & $0.032^{*}$ \\
\hline $\begin{array}{l}\text { Income (Saudi Real) } \\
\leq 5000\end{array}$ & $35(32.7 \%)$ & $46(36.5 \%)$ & 0.464 \\
$>5000$ & $72(67.3 \%)$ & $80(63.5 \%)$ & \\
\hline Health status & & & \\
Good & $67(62.6 \%)$ & $53(42.1 \%)$ & $0.001^{* *}$ \\
Not well & $30(28 \%)$ & $65(51.6 \%)$ & \\
Poor & $10(9.4 \%)$ & $8(6.3 \%)$ & \\
\hline
\end{tabular}




\begin{tabular}{llll}
\hline \multicolumn{2}{l}{ Anthropometric measurements and indicators } & & \\
\hline Weight $(\mathrm{kg})$ & $53.52 \pm 7.09$ & $59.05 \pm 12.85$ & $0.003^{*}$ \\
$\mathrm{BMI}\left(\mathrm{kg} / \mathrm{m}^{2}\right)$ & $21.42 \pm 2.79$ & $23.78 \pm 6.41$ & $0.000^{*}$ \\
Underweight & $13(12.1 \%)$ & $19(15.1 \%)$ & $0.000^{* *}$ \\
Normal & $83(77.6 \%)$ & $66(52.4 \%)$ & \\
Overweight & $10(9.3 \%)$ & $29(23 \%)$ & \\
Obesity & $1(0.9 \%)$ & $12(9.5 \%)$ & $0.002^{*}$ \\
\hline Waist circumference $(\mathrm{cm})$ & $71.32 \pm 11.41$ & $80.49 \pm 15.35$ & $0.045^{*}$ \\
Normal $(<88 \mathrm{~cm})$ & $98(91.6 \%)$ & $78(61.9 \%)$ & \\
At risk $(\geq 88)$ & $9(8.4 \%)$ & $48(38.1 \%)$ & \\
\hline Body fat percentage & & & $0.020^{*}$ \\
Normal $(\leq 29.9 \%)$ & $69(64.4 \%)$ & $76(60.3 \%)$ & \\
Moderate/high $(\geq 30 \%)$ & $38(35.6 \%)$ & $50(39.7 \%)$ & $0.003 *$ \\
\hline Daily sleep hours & $7.35 \pm 1.43$ & $5.89 \pm 1.15$ & \\
\hline$* \mathrm{P}<0.05, * * \mathrm{P}<0.001$ & & & \\
\hline
\end{tabular}

Table 2. Difference in PSQI component score between good and poor sleepers

\begin{tabular}{llll}
\hline Components & (PSQI) $\leq 5$ & $($ PSQI $)>5$ & P-value \\
& Good sleepers & Poor sleepers & \\
& $107(46 \%)$ & $126(54 \%)$ & \\
\hline Component 1: Sleep quality & $0.69 \pm 0.71$ & $1.29 \pm 0.83$ & $0.000^{* *}$ \\
Component 2: Sleep latency & $0.65 \pm 0.54$ & $1.48 \pm 0.83$ & $0.000^{* *}$ \\
Component 3: Sleep duration & $0.83 \pm 0.62$ & $1.37 \pm 0.71$ & $0.000^{* *}$ \\
Component 4: Sleep efficiency & $0.75 \pm 068$ & $1.34 \pm 0.76$ & $0.000^{* *}$ \\
Component 5: Sleep disturbance & $0.39 \pm 0.23$ & $1.46 \pm 0.85$ & $0.000^{* *}$ \\
Component 6: Use of sleep medication & $0.38 \pm 0.24$ & $0.56 \pm 0.39$ & $0.000^{* *}$ \\
Component 7: Daytime dysfunction & $0.74 \pm 0.57$ & $1.64 \pm 0.93$ & $0.000^{* *}$ \\
Total PSQI score & $4.43 \pm 1.38$ & $9.14 \pm 1.69$ & $0.000^{* *}$ \\
\hline$* * \mathrm{P}<0.001$ & & & \\
\hline
\end{tabular}

Table 3. Difference in physical activity and lifestyle habits between good and poor sleepers

\begin{tabular}{llll}
\hline Variables & $\begin{array}{l}\text { (PSQI) } \leq 5 \\
\text { Good sleepers } \\
107(46 \%)\end{array}$ & $\begin{array}{l}\text { PSQI })>5 \\
\text { Poor sleepers } \\
126(54 \%)\end{array}$ & \\
\hline Physical activity $(M E T)$ & $1363.64+112.63$ & $1025.32+102.82$ & $0.016^{*}$ \\
\hline Physical activity levels & & & $0.011^{*}$ \\
low & $31(29 \%)$ & $54(42.9 \%)$ & \\
Moderate & $40(37.4 \%)$ & $50(39.7 \%)$ & \\
High & $36(33.6 \%)$ & $22(17.5 \%)$ & \\
\hline Skipping breakfast & & & \\
$<3$ times/week & $56(52.3 \%)$ & $31(24.6 \%)$ & \\
$\geq 3$ times/week & $51(47.7 \%)$ & $95(75.4 \%)$ & \\
\hline
\end{tabular}




\begin{tabular}{llll}
\hline $\begin{array}{l}\text { Eating fruit and vegetable } \\
<3 \text { times/week }\end{array}$ & $60(56.1 \%)$ & $99(78.6 \%)$ & $0.031^{*}$ \\
$\geq 3$ times/week & $47(43.9 \%)$ & $27(21.4 \%)$ & \\
\hline Drinking coffee and tea & & & \\
$<3$ times/week & $44(41.1 \%)$ & $46(36.5)$ & 0.501 \\
$\geq 3$ times/week & $63(58.9 \%)$ & $80(63.5 \%)$ & \\
\hline Using internet in bed & & & \\
Yes & $40(37.4 \%)$ & $57(45.2 \%)$ & \\
No & $67(62.6)$ & $69(54.8 \%)$ & \\
\hline$* \mathrm{P}<0.05$ & & & \\
\hline
\end{tabular}

Table 4. Association between sleep quality, different measures of obesity, and lifestyle habits

\begin{tabular}{|c|c|c|c|}
\hline Variables & P-value & Odds ratio & $95 \%$ Confidence Interval \\
\hline \multicolumn{4}{|l|}{ Body Mass Index } \\
\hline Underweight/normal & Reference & & \\
\hline Overweight/obesity & $0.000 * *$ & 4.210 & $2.035-8.707$ \\
\hline \multicolumn{4}{|l|}{ Waist circumference } \\
\hline Normal $(<88 \mathrm{~cm})$ & Reference & & \\
\hline At risk $(\geq 88)$ & $0.009^{*}$ & 2.055 & $0.893-4.727$ \\
\hline \multicolumn{4}{|l|}{ Body fat percentage } \\
\hline Normal $(\leq 29.9 \%)$ & Reference & & \\
\hline Moderate/high $(\geq 30 \%)$ & $0.025^{*}$ & 1.058 & $0.966-1.160$ \\
\hline \multicolumn{4}{|l|}{ Physical activity levels } \\
\hline High & Reference & & \\
\hline Moderate & 0.471 & 1.215 & $0.716-2.061$ \\
\hline low & $0.037^{*}$ & 2.045 & $1.043-4.013$ \\
\hline \multicolumn{4}{|l|}{ Skipping breakfast } \\
\hline$<3$ times/week & Reference & & \\
\hline$\geq 3$ times/week & $0.003^{*}$ & 2.710 & $1.416-5.185$ \\
\hline \multicolumn{4}{|c|}{ Eating fruit and vegetable } \\
\hline$<3$ times/week & 0.114 & 2.124 & $1.162-3.882$ \\
\hline$\geq 3$ times/week & Reference & & \\
\hline
\end{tabular}

\section{Discussion}

PSQI scores indicated that poor sleep quality was common in the female students (54\%) who only slept an average of five hours/day. As in prior studies, a similar proportion (58.7\%) of Lebanese students reported poor sleep quality, but they had longer total sleeping hour (6.75 $\$ 3.49$ hours/day) (Kabrita et al.,2014), whereas 54.7\% of university students in Taiwan were also classified as poor sleepers (Cheng et al.,2012). However, a cross sectional survey conducted among female medical students from Jazan University in Saudi Arabia reported a higher prevalence $(69.1 \%)$ of students suffering from poor sleep quality with only an average of 4.77 hours/night than in our study (Mahfouz et al., 2013). Together, these results suggest that students commonly experience sleep deficits including shorter sleep time. 
In terms of the various components of sleep measured by the PSQI, students in our study reported significantly higher mean scores on all seven components of the scale, especially daytime dysfunction, with similar results reported among Jordanian university students (Suleiman et al., 2013) and students from Hong Kong (Tsui et al., 2009).

Increasing physical activity levels is a current national health objective in Saudi Arabia (MOH,2015). Several studies have found that physical activity can exert a positive effect on sleep duration and quality (Brondel et al., 2010). Consistent with this result, the present study found a significant difference between the groups, with the poor sleepers engaging in less physically activity and with the lowest MET minutes/week score relative to the good sleepers, which is supported by the results of an earlier study by Knutson (2005), who found that $40 \%$ of the poor sleepers reported waking up tired every morning which had a negative effect on their daily physical activity levels. Similar to our findings, a recent study (McClain et al., 2014) found that younger adults (20-39 years) who experienced adequate sleep duration and quality exercised more often on a daily basis physical activities than those with poor sleep quality $(\mathrm{P}=0.05)$. However, another study conducted among Lebanese students did not find any significant differences or association for physical activity MET minutes/week score and level of physical activity (Kabrita et al., 2014).

Poor sleep quality may also affect our eating patterns. In the present study, skipping breakfast, drinking tea/coffee more than three times/week, and less intake of fruit/vegetable were more prevalent among the poor sleepers, relative to good sleepers. Kim et al. (2010) reported similar results finding that the women who slept for a short time ( $<5$ hour daily) ate less fruits/vegetables, tended to skip breakfast, and consume more calories from fats and sweets. They also tended to consume most of their food at night so that they woke in the morning not hungry and replacing breakfast with an early morning snack. Moreover, Cheng et al. (2012) reported that female undergraduate students who were classified as poor sleepers tended to skip breakfast and drink tea. Furthermore, our modern lifestyles with high-speed internet availability and social media apps and program may affect our sleep quality. In Saudi Arabia, 35\% of the population uses the internet daily. For example, studies have found that internet usage is associated with poor sleep quality (Wolniczak et al., 2013). Despite this, we did not find a significant difference in the nighttime internet usage of poor and good sleepers. This non-significant difference may be due to the expected high internet usage of university students, relative to non-students.

In addition, participants with children were 3-times more likely to be poor sleepers, and they might also be likely to skip breakfast, drink tea/coffee at night to stay awake with children, and work on the internet in bed, in an attempt to adapt to the high workload of parenting which is affecting the sleep quality. Studies of sleep quality and duration in the United States of America found that parents with children were more likely to get less sleep than those without children, consume more caffeine, tended to eat more food at night, did more physical work as household chores, that affects parents' bedtimes and rise times (Krueger et al., 2009; Leonhard and Randler, 2009; Butt et al., 2015).

Among the poor sleepers, overweight/obesity, at risk waist circumference, and moderate/high body fat percentage were associated with poor sleep quality. Several studies support our results such as Yeh and Brown (2014) who explored the relationship between poor sleep quality and BMI. They found that high BMI was associated with short sleep duration, increased sleep latency, and use of sleep medications. Mezick et al. (2014) also investigated associations between subjective and objective sleep measures and different measures of obesity in 1248 adults aged 34-84 years. They found that high BMI and waist circumference were associated with shorter and less efficient sleep only in women. In addition, poor sleep quality was inversely associated with waist circumference in 400 Swedish females, aged 20-70 years (Theorell-Haglow et al., 2010). Further, a recent study found greater BMI and body fat percent were associated with low sleep quality among male and female Americans aged 21-35 years (Wirth et al., 2015). The possible explanation of the above finding is that insufficient sleep may increase energy needs, dietary consumption, the tendency to skip breakfast, eat less fruit/vegetables, and eat more each day and/or it may impact on hunger and satiety hormones (e.g. leptin and ghrelin) which have been observed to occur in association with short sleep duration, and it is an independent risk factor for weight gain and obesity (Markwald et al., 2013).

However, contrary to our finding, Kamath and colleagues (2014) found that short sleep duration and quality were not significantly associated with overweight/obesity in Malaysian university students $(\mathrm{P}=0.65)$, with similar results reported by Pengpid and Peltzer (2014) who found that shorter sleep duration was not associated with overweight/obesity and waist circumference in female Indian university students, although longer sleep duration was associated. Finally, at risk waist circumference and high body fat have been shown to be associated with low physical activity levels and skipping breakfast, similar to Cheng et al. (2012) who found that skipping breakfast $(\mathrm{P}=0.001)$, tea drinking $(\mathrm{P}=0.026)$ and internet addiction $(\mathrm{P}=0.0002)$ were associated with poor sleep quality in 
female undergraduate students in Taiwan. Further, in middle- and older-aged Chinese women, Tu et al. (2014) find low fruit consumption was associated with short sleep duration ( $<5$ hour daily), but no association was reported for vegetable and tea intake.

The present study has limitations. First, it was conducted only in female students in one college, which might not be representative of other colleges or universities. Second, it was a cross sectional study design, thus, the associations do not provide an insight into causality, or the direction of causality. Third, a convenience sample of volunteer students participated in the study, and this may have led to selection bias. For example, some overweight participants may have self-selected into the study or elsewise they may have avoided participating, due to their sensitivity to this issue (Latner et al., 2005). However, most of the students who participated in our study were of normal weight. Finally, we did not study the association between dietary intakes (e.g. energy intake, macronutrients) and sleep quality, which might have been related to the measures of obesity.

Despite these limitations, this study has several strengths. The present study involved conducting individual interviews and the collection of anthropometric measurements and the PSQI data was collected by the researchers. To our knowledge, this is the first study to examine the association between sleep quality and different measures of obesity among female university students in Saudi Arabia.

\section{Conclusion}

The present study highlights the prevalence of poor sleep quality in female university students in Saudi Arabia. Our findings support previously published studies indicating that poor sleep quality was associated with overweight/obesity, high body fat percentage, high waist circumference, low physical activity levels, and certain lifestyle habits (skipping breakfast). Future studies should seek to examine the associations between diet, internet usage, academic achievement and sleep quality. Sleep quality is a potential untraditional way in which overweight/obesity may be prevented and treated.

\section{Conflict of Interest}

The authors declare that there is no conflict of interests regarding the publication of this paper.

\section{References}

Al-Hazzaa, H. M. (2006). Health-enhancing physical activity among Saudi adults using The International Physical Activity Questionnaire (IPAQ). Public Health Nutrition, 10(1), 59-64.

Al-Hazzaa, H. M., Musaiger, A. O., Abahussain, N., Al-Sobayel, H., \& Qahwaji, D. (2012). Prevalence of short sleep duration and its association with obesity among Saudi adolescents15- to 19-year olds: A cross-sectional study from three major cities in Saudi Arabia. Annals of Thoracic Medicine, 7, 133-139. http://dx.doi.org/10.4103/1817-1737.98845

Bahammam, A. S. (2011). Sleep medicine in Saudi Arabia: Current problems and future challenges. Ann Thorac Med, 6, 3-10. http://dx.doi.org/10.4103/1817-1737.74269

Bayon, V., Leger, D., Gomez-Merino, D., Vecchierini, M. F., \& Chennaoui, M. (2014). Sleep debt and obesity. Ann Med, 46, 264-72. http://dx.doi.org/10.3109/07853890.2014.931103

Bawazeer, N. M., Al-Daghri, N. M., Valsamakis, G., Al-Rubeaan, K. A., Sabico, S. L., \& Huang, T. T., (2009). Sleep duration and quality associated with obesity among Arab children. Obesity, 17, 2251-3. http://dx.doi.org/10.1038/oby.2009.169

Brondel, L., Romer, M.A., Nougues, P.M., Touyarou, P., \& Davenne, D. (2010).Acute partial sleep deprivation increases food intake in healthy men. Am $J$ Clin Nutr, 91, 1550-9. http://dx.doi.org/10.3945/ajcn.2009.28523

Butt, M., Quan, S. F., Pentland, A.S., \& Khayal, I. (2015). Gender differences in real-home sleep of young and older couples. Southwest J Pulm Crit Care, 10(5), 289-299. http://dx.doi.org/10.13175/swjpcc068-15

Buysse, D. J., Reynolds, C. F., Monk, T. H., Bermanand, S. R., \& Kupfer, D. J. (1898). The Pittsburgh Sleep Quality Index: A new instrument for psychiatric practice and research. Psychiatry Res, 28, 193-213. http://dx.doi.org/10.1016/0165-1781(89)90047-4

Chaput, J. P., Perusse, L., Despres, J. P., Tremblay, A., \& Bouchard, C. (2014). Findings from the Quebec Family Study on the etiology of obesity: Genetics and environmental highlights. Curr Obes Rep, 3, 54-66. http://dx.doi.org/10.1007/s13679-013-0086-3

Cheng, S.H., Shih, C.C., Lee, I.H., Hou, Y.W., Chen, K.C., \& Chen, K.T. (2012). A study on the sleep quality of incoming university students. Psychiatry Res, 197, 270e4. 
Darwish, M. A., Al Turki, Z. A., Sabra, A. A., Sebiany, A. M., Kumar, H., \& Palaha, R. A. (2014). Obesity among females attending Al-Qatif health care centers, Eastern Saudi Arabia: Prevalence and associated factors. Int. J. Med. Sci. Public Health, 3, 1144-1149. http://dx.doi.org/10.5455/ijmsph.2014.070720141

Kabrita, C. S., Hajjar-Muca, T. A., \& Duffy, J. F. (2014). Predictors of poor sleep quality among Lebanese university students: Association between evening typology, lifestyle behaviors, and sleep habits. Nature and Science of Sleep, 6, 11-18.

Kamath, M. G., Prakash, J., Dash, S., Chowdhury, S., Ahmed, Z. B., \& Mohd Yusof, M. Z. Z. (2014). Is there an Association between self-reported Sleep duration, body mass index and waist-hip ratio in young Adults? A cross- sectional pilot study. Journal of Clinical and Diagnostic Research, 9, BC05-BC07. http://dx.doi.org/10.2147/NSS.S55538

Kim, S., Deroo, L.A., \& Sandler, D. P. (2011). Eating patterns and nutritional characteristics associated with sleep duration. Public Health Nutr, 14, 889-95. http://dx.doi.org/10.1017/S136898001000296X

Knutson, K. L. (2005). The association between pubertal status and sleep duration and quality among a nationally representative sample of $\mathrm{U}$. S. adolescents. Am $J$ Hum Biol, 17, 418-24. http://dx.doi.org/10.1002/ajhb.20405

Knutson, K. L., Cauter, V., Rathouz, P. J., Deleire, T., \& Lauderdale, D. S. (2010). Trends in the prevalence of short sleepers in the USA: 1975-2006. Sleep, 33, 37-45.

Krueger, P. M., \& Friedman, E. M. (2009). Sleep duration in the United States: a cross-sectional population-based study. Am J Epidemiol, 169, 9, 1052-1063. http://dx.doi.org/10.1093/aje/kwp023.

Latner, J. D., Stunkard, A. J., \& Wilson, G. T. (2005) .Stigmatized students: age, sex, and ethnicity effects in the stigmatization of obesity. Obesity Res., 13, 1226-1231. http://dx.doi.org/10.1038/oby.2005.145

Leonhard, C., \& Randler, C. (2009). In sync with the family: children and partners influence the sleep-wake circadian rhythm and social habits of women. Chronobiol Int, 26(3), 510-525. http://dx.doi.org/10.1080/07420520902821101.

Mahfouz, M. S., Ageely, H., Al- Saruri, M., Aref, L. A., Hejje, N. H., Al-attas, S. A., ... Bani, I.A. (2013). Sleep quality among students of the faculty of Medicinein Jazan University, Saudi Arabia. Middle-East Journal of Scientific Research. 16(4), 508-513.

Markwald, R. R., Melanson, E. L., \& Smith, M. R. (2013). Impact of insufficient sleep on total daily energy

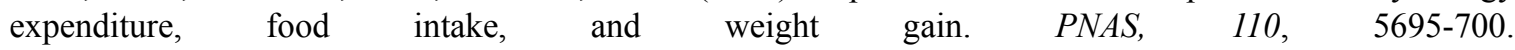
http://dx.doi.org/10.1073/pnas.1216951110

McClain, J. J., Lewin, D. S., Laposky, A. D., Kahle, L., \& Berrigan, D. (2014). Associations between physical activity, sedentary time, sleep duration and daytime sleepiness in US adults. Prev. Med, 66, 68-73. http://dx.doi.org/10.1016/j.ypmed.2014.06.003

Memish, Z. A., El Bcheraoui, C., Tuffaha, M., Robinson, M., Daoud, F., \& Jaber, S. (2014). Obesity and Associated Factors Kingdom of Saudi Arabia. Prev. Chronic Dis, 11, 140236. http://dx.doi.org/10.5888/pcd11.140236

Mezick, E. J., Wing, R. R., \& McCaffery, J. M. (2014). Associations of self-reported and actigraphy-assessed sleep characteristics with body mass index and waist circumference in adults' moderation by gender. Sleep Med, 15, 64-70. http://dx.doi.org/10.1016/j.sleep.2013.08.784

Minstriy of Health, National Campaign against Overweight and Obesity. Retrieved November $20^{\text {th }}$, 2015, from http://www.moh.gov.sa/en/HealthAwareness/ Campaigns/badana/Pages/default.aspx.

National Sleep Foundation of America: Sleep in America Poll. Washington, 2009.

Pengpid, S., \& Peltzer, K. (2014). Prevalence of overweight/obesity and central obesity and its associated factors among a sample of university students in India. Obes Res Clin Pract, 8, e558-570. http://dx.doi.org/10.1016/j.orcp.2013.12.003

Schmid, S. M., Hallschmid, M., Jauch-Chara, K., Wilms, B., Benedict, C., \& Lehnert, H. (2009). Short-term sleep loss decreases physical activity under free-living conditions but does not increase food intake under time-deprived laboratory conditions in healthy men. Am $J$ Clin Nutr, 90, 1476-82. http://dx.doi.org/10.3945/ajen.2009.27984

Suleiman, K. H., Yates, B. C., Jassem, H., Alghabeesh, S., Abu-Shahroor, L., \& Ali, R. (2013). Sleep 
disturbances among Alzaytoonah uni-versity students in Jordan. J Nat Sci Res, 12, 39-46.

Taheri, S. (2006).The link between short sleep duration and obesity: we should recommend more sleep to prevent obesity. Arch Dis Child, 9, 81-84. http://dx.doi.org/10.1136/adc.2005.093013

Theorell-Haglow, J., Berne, C., \& Janson, C. (2010). Associations between short sleep duration and central obesity in women. Sleep, 33, 593-8.

Tsui, Y., \& Wing, Y. (2009). A study on the sleep patterns and problems of university business students in Hong Kong. J. Am. Coll. Health, 58, 167-176. http://dx.doi.org/10.1080/07448480903221418

Tu, X., Cai, H., \& Gao Y. T. (2012). Sleep duration and its correlates in middle-aged and elderly Chinese women: the Shanghai Women's Health Study. Sleep Medicine, 13(9), 1138-1145. http://dx.doi.org/10.1016/j.sleep.2012.06.014

Vasudev, S., Mohan, A., Mohan, D., Farooq, S., Raj, D., \& Mohan, V. (2004). Validation of body fat measurement by skinfolds and two bioelectric impedance methods with DEXA - The Chennai Urban Rural Epidemiology Study (CURES-3). JAPI. 52, 877-881.

Yeh, S. S. S., \& Brown, R. F. (2014). Disordered eating partly mediates the relationship between poor sleep quality and high body mass index. Eating Behaviors, 15, 291-297. http://dx.doi.org/10.1016/j.eatbeh.2014.03.014

Wirth, M. D., Hébert, J. R., \& Hand, G. A. (2015). Association between actigraphic sleep metrics and body composition. Ann Epidemiol, 25, 773-778. http://dx.doi.org/10.1016/j.annepidem.2015.05.001

Wolniczak, I., Ca'ceres-Del Aguila, J. A., Palma-Ardiles, G., Arroyo, K. J., \& Solıs-Visscher, R. (2013). Association between facebook dependence and poor sleep quality: A study in a sample of undergraduate students in Peru. PLoS ONE, 8, e59087. http://dx.doi.org/10.1371/journal.pone.0059087

World Health Organization, Obesity and overweight. Retrieved November 20 $0^{\text {th }}$, 2015, from http://www.who.int/mediacentre/factsheets/fs311/en/ .2014.

World Health Organization, Obesity: Preventing and Ma- nagging the Global Epidemic. Report of a World Health Organization Consultation on Obesity. 1998.

\section{Copyrights}

Copyright for this article is retained by the author(s), with first publication rights granted to the journal.

This is an open-access article distributed under the terms and conditions of the Creative Commons Attribution license (http://creativecommons.org/licenses/by/3.0/). 